\title{
Multifocal nodular steatosis mimicking liver metastasis
}

\author{
Esteatose nodular multifocal simulando metástases hepáticas
}

\author{
Eduardo Kaiser Ururahy Nunes Fonseca ${ }^{1}$, Thiago Raspa Freitas Magdalena ${ }^{1}$, Fernando Ide Yamauchi ${ }^{1}$, \\ Marcelo de Castro Jorge Racy ${ }^{1}$, Cássia Franco Tridente ${ }^{1}$, Ronaldo Hueb Baroni ${ }^{1}$
}
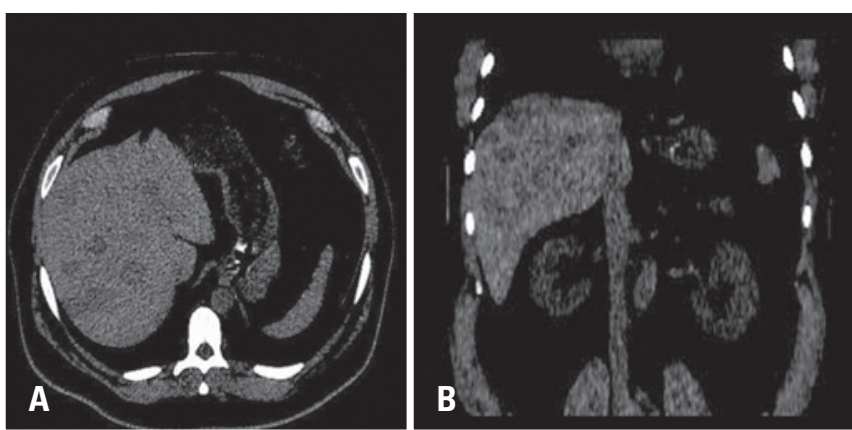

Figure 1. (A) Non-enhanced computed tomography on axial A coronal reformatted. (B) Showing multiple hypoattenuating liver nodules
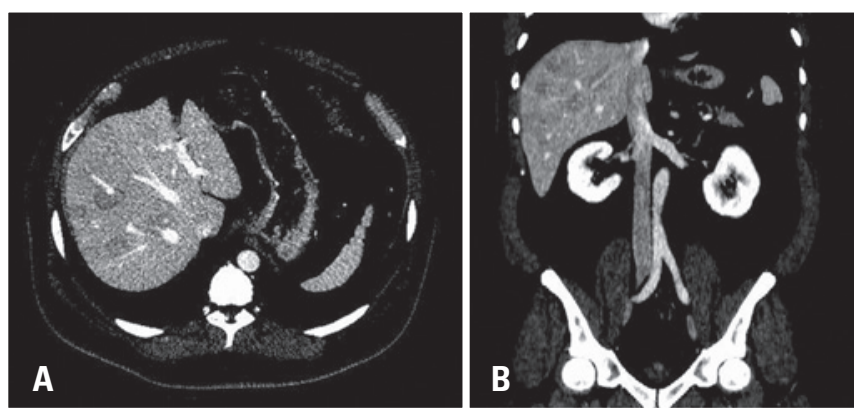

Figure 2. (A) Post-contrast computed tomography on axial A and coronal reformatted. (B) Showing multiple hypoattenuating liver nodules. Notice vascular structures crossing inside the nodules without deviations indicating lack of mass effect

We report a case of a 56-year-old male under investigation for large lytic lesion at clivus. After lesion resection, patient was referred to abdominal computed tomography scan for metastasis screening. The lesion was posteriorly characterized as chondroid chordoma at histopathology examination.
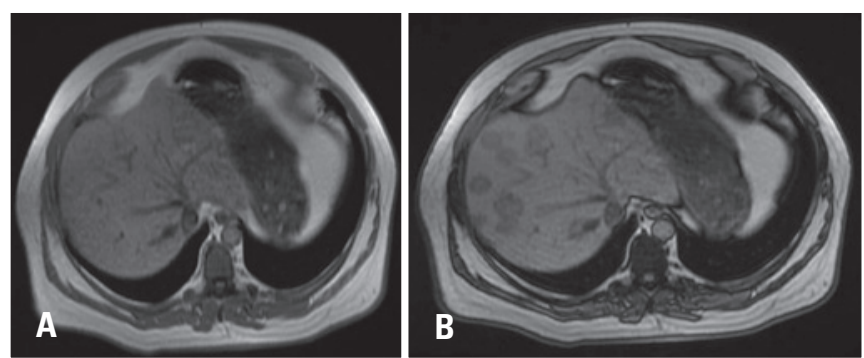

Figure 3. Magnetic resonance imaging in gradient echo sequences.

(A) In-phase and out-of-phase images. (B) Show signal drop on the latter, indicating intracellular lipid content

On non-enhanced computed tomography, multiple hypottenuating nodules of different sizes were seen; the largest nodule had $3.2 \mathrm{~cm}$. On post-contrast phases lesions had similar enhancement to adjacent liver parenchyma. However, no significant mass effect or invasiveness were seen, once vascular structures (liver veins and portal branches) crossed such nodules without dislocation or invasion. Our findings, although not pathognomonic, suggested the hypothesis of multifocal nodular steatosis.

In order to confim the diagnosis, patient underwent a magnetic resonance imaging (MRI) that further characterized lipid within the lesions. On MRI this characteristic can be explored by chemical shift technique in which there is signal drop on out-of-phase sequence compared to in-phase sequence.

Fat deposits in liver parenchyma are frequent and have a prevalence of $15 \%$ in general population. ${ }^{(1,2)}$ Nodular patterns are uncommon, and can be mistaken for metastasis, which is particularly problematic in

\footnotetext{
${ }^{1}$ Hospital Israelita Albert Einstein, São Paulo SP, Brazil.

Corresponding author: Fernando Ide Yamauchi - Avenida Albert Einstein, 627/701 - Morumbi - Zip code: 05652-900 - São Paulo, SP, Brazil - Phone: (55 11) 2151-0195 - E-mail: fernando.yamauchi@einstein.br Received on: Sep 16, 2016 - Accepted on: Jan 5, 2017

DOI: $10.1590 /$ S1679-45082017Al3869
} 
oncologic patients. In our case, patient had a chordoma, a rare tumor that can present with metastasis in 3 to $48 \%$ of cases - and about one fifth of them are located in the liver. ${ }^{(3)}$

Imaging findings such as lack of invasion or displacement of vascular structures, enhancement similar to normal liver parenchyma and stability over time corroborate the diagnosis. Magnetic resonance imaging is very helpful to confirm this diagnosis with signal drop on out-of-phase sequence compared to in-phase sequence, confirming intracellular lipid content. . $^{(2,47)}$

\section{REFERENCES}

1. Angulo P. Nonalcoholic fatty liver disease. N Engl J Med. 2002;346(16):1221-31. Review.
2. Hamer OW, Aguirre DA, Casola G, Lavine JE, Woenckhaus M, Sirlin CB. Fatty liver: imaging patterns and pitfalls. Radiographics. 2006;26(6):1637-53. Review.

3. Chambers PW, Schwinn CP. Chordoma. A clinicopathologic study of metastasis. Am J Clin Pathol. 1979;72(5):765-76. Review.

4. Kemper J, Jung G, Poll LW, Jonkmanns C, Lüthen R, Moedder U. CT and MRI findings in multifocal hepatic steatosis mimicking malignancy. Abdom Imaging. 2002;27(6):708-10.

5. Kröncke TJ, Taupitz M, Kivelitz D, Scheer I, Daberkow U, Rudolph B, et al. Multifocal nodular fatty infiltration of the liver mimicking metastatic disease on CT: imaging findings and diagnosis using MR imaging. Eur Radiol. 2000; 10(7):1095-100.

6. Tebala GD, Jwad A, Khan AQ, Long E, Sissons G. Multifocal nodular fatty infiltration of the liver: a case report of a challenging diagnostic problem. Am J Case Rep. 2016;17:196-202.

7. Siegelman ES, Chauhan A. MR characterization of focal liver lesions: pearls and pitfalls. Magn Reson Imaging Clin N Am. 2014;22(3):295-313. Review. 